\title{
SURFACE TOPOGRAPHY OF OPERATED SLIDE JOURNAL MICRO-BEARINGS USED IN HDD
}

\author{
Andrzej Miszczak \\ Gdynia Maritime University, Faculty of Marine Engineering \\ Morska Street 83, 81-225 Gdynia, Poland \\ tel.: +48 58 6901348, fax number: +48586901399 \\ e-mail address:miszczak@am.gdynia.pl
}

\begin{abstract}
In this paper author present results of measurements of slide journal micro-bearings surface topography measured with an atomic force microscope (AFM). The results of measurements of surface topography were presented in the form of surface topography maps, three-dimensional graphs and some examples of selected cross-sections of investigated surface in the form of profile graphs.

Measurements of surface topography were made for journals and sleeves of slide journal micro-bearings from personal computers' hard disc drives, with the Atomic Force Microscope NT-206 produced in MTM in Minsk, Republic of Belarus.

In this research author used two identical sets of micro-bearings from 2.5" HDD Samsung HM160HI 5400rpm and 3.5" HDD Seagate Barracuda 7200.10 ST380815AS 7200 rpm hard disc drives. First set of those four microbearings worked for a year at rated RPM continuously (i.e. 24 hours a day). Second set of the same micro-bearings also worked for a year at rated RPM, but in intermittent mode (i.e. 15 minutes on, 15 minutes off).

The values of profile roughness parameters $R_{a}$ and $R_{q}$ and the distance between maximum peak height and maximum valley depth are presented as well.

The application SurfaceXplorer ${ }^{\circledR}$ was used for processing and visualization of the data obtained from AFM NT-206, which besides from generating $2 D, 3 D$ and profile diagrams, was used to calculate and draw graph of height distribution.

Surface topography of investigated bearings sleeves was also measured using Hommeltester T8000-R60 profilometer. Those measurements give information about micro-grooves dimensions and location.

On the surfaces of studied micro-bearings, some micro-grooves can be found in form of herringbone, with depth about $1.5 \mu \mathrm{m}$ and width $150 \mu \mathrm{m}$. Received information about micro-grooves geometry will allow developing proper theory of hydrodynamic lubrication for micro-bearings with micro-grooves.
\end{abstract}

Keywords: atomic force microscope, surface topography, micro-grooves, herringbone grooves, micro bearing in $H D D$.

\section{Introduction}

Surface roughness of the slide journal micro-bearings is more significant for the flow parameters in the bearing gaps than in the case of classical slide journal bearings, especially large ones, used for example in the ship crankshafts or main engine shafting bearings. It results from the surface roughness height value to the radial clearance ratio. Because of that, while making the project calculations on the flow and operational parameters of the small-sized bearings ( $1 \mathrm{~mm}-50 \mathrm{~mm}$ diameter), it is important to take into consideration the influence of the roughness height on the change of oil clearance height. It can make with the stochastic methods $[1,5,8,11]$. To perform the calculation, the stochastic changes of the oil gap height and probability density function has to be determined. Such function can be determined on the basis of the bearing's journal and sleeve surface topography $[1,5,8]$. Another factor that has an influence on the change of flow and operational parameters inside the oil clearance of the slide journal are the micro-grooves located on the surface of the bearing's sleeve or journal $[2,3,6,7,9]$.

The purpose of this work is to create the surface topography of the bearing journals and sleeves of the slide journal micro-bearings used in the HDD drives and to define the size of the micro-grooves. 
The measurement of the surface topography in the macro scale was made with use of the Hommeltester T8000-R60 profilometer. Thanks to the results of these measurements, the information on the size and the location of the micro-grooves on the surface of the bearing sleeves were obtained. To perform the measurement, the area 2-4 millimetres long and 250-300 $\mu \mathrm{m}$ wide was scanned.

Measurements of surface roughness in micro and nanoscale can be executed with atomic force microscope. In the research, the author of this paper used the Atomic Force Microscope NT-206 produced in MTM in Minsk, Republic of Belarus.

Atomic Force Microscope NT-206 provides findings for samples with maximum roughness value $\pm 1 \mu \mathrm{m}$. Max. field in one scanning process is up to $32 \mu \mathrm{m} \times 32 \mu \mathrm{m}$. Measurements were preceded with resolution $256 \times 256$ points. The process of surface scanning was made in the static (contact) mode.

The author had researched the surface topography of four used journals and sleeves of the slide journal micro-bearings used in HDD drives. In the research, the author of this paper used two identical sets of HDD drives: 2.5" HDD Samsung HM160HI - 5400rpm and 3.5" HDD Seagate Barracuda 7200.10 ST380815AS - $7200 \mathrm{rpm}$. HDD drives are equipped with the slide journal micro-bearings with micro-grooves on the surface of the inside sleeve in form of the herringbone. The first HDD set was working for a year at rated RPM continuously (i.e. 24 hours a day). The second set of the same HDD was working also for a year at rated RPM but in intermittent work mode (that is 15 minutes on - 15 minutes off). In the previous works, the surface topography measurement was made on the identical, unused slide journal microbearings [4]. Thanks to the comparison of the surface topography obtained earlier and topography obtained now, the analysis of the slide surface wearing level can be made. Picture 1 presents the working set with fans and HDD drives working in the continuous and intermittent modes.

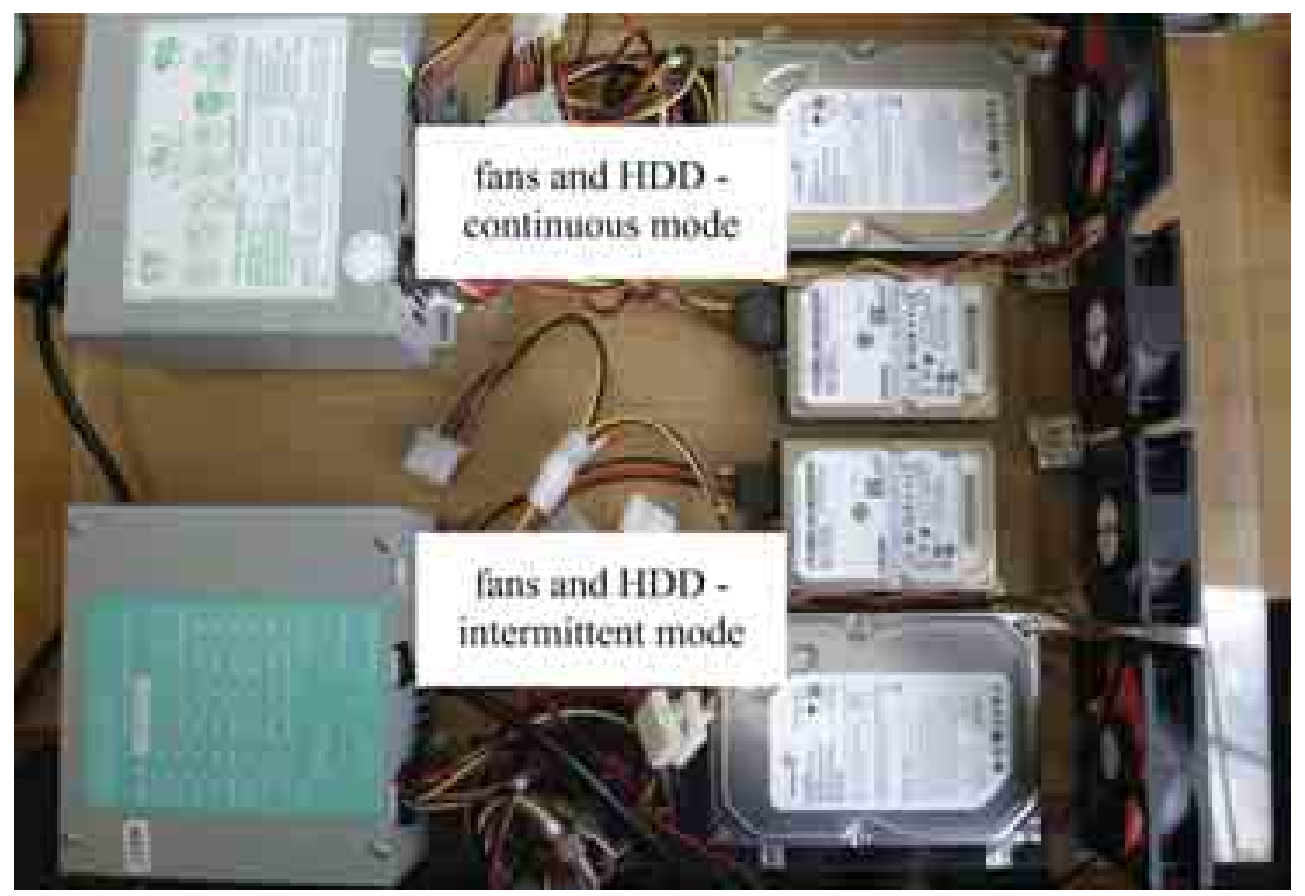

Fig. 1. Working sets of computers hard disk drives and fans

\section{Measurements of surface topography}

Surface topography of the slide journal micro-bearing sleeve used in Samsung HM160HI HDD drive that was working in continuous mode is presented on Fig. 2. The Fig. 3 presents the surface 
topography of the slide journal micro-bearing sleeve used in Samsung HM160HI that was working in intermittent mode. Fig. 2a and 3a presents surface topography made on the profilometer and the Fig. $2 \mathrm{~b}$ and $3 \mathrm{~b}$ presents the topography made on AFM NT-206. The surface topography is presented in 2D and 3D view. Pictures also show the cross-section and the roughness, as well as height distribution and tilts orientation.
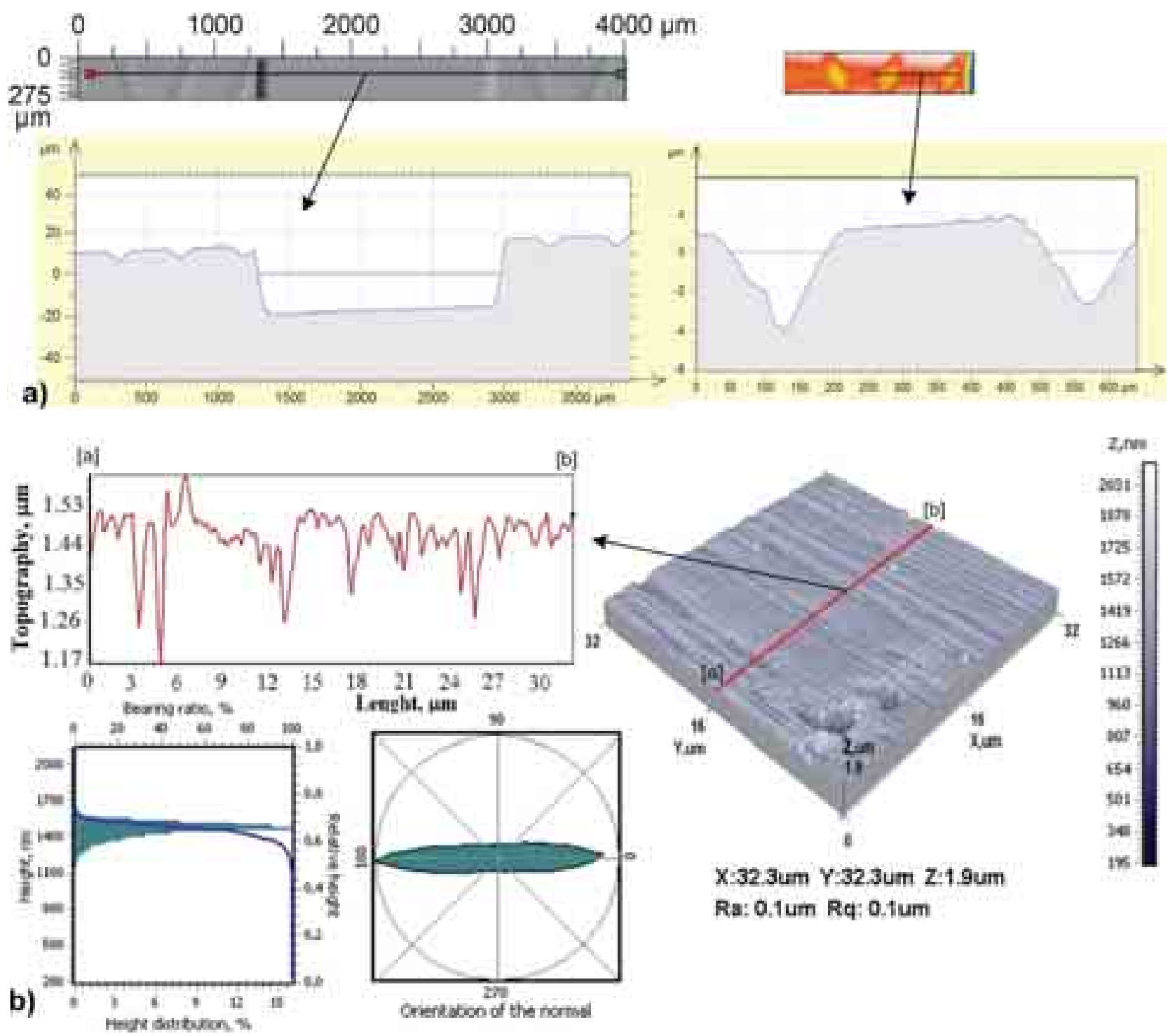

Fig. 2. Bearing sleeve's surface with micro-grooves - bearing from HDD Samsung HM160HI-continuous mode

The surface topography of the slide journal micro-bearing sleeve used in the HDD Seagate Barracuda 7200.10 ST380815AS that was working in continuous mode is presented on Fig. 4, and the same device that was working in intermittent mode is presented on Fig. 5. Fig. 4a and 5a presents surface topography made on the Hommeltester T8000-R60 profilometer and the Fig. 4b and $5 \mathrm{~b}$ presents the topography made on AFM NT - 206.

The micro-grooves, on the internal surface of the slide journal micro-bearing's sleeve, used in the HDD Samsung HM160HI (see Fig. 2 and 3) are about $5 \mu \mathrm{m}$ deep and about $175 \mu \mathrm{m}$ wide and their cross-section is triangular. The spaces between the micro-grooves are about $250-275 \mu \mathrm{m}$ wide.

On the surface of the slide journal, micro-bearing sleeve used in HDD Samsung HM160HI the scratches, grooves and material losses can be observed. The sleeve was made from the GB 4239 material (China) and the journal was made from the X20Cr13 EN10250-4 material [10]. 

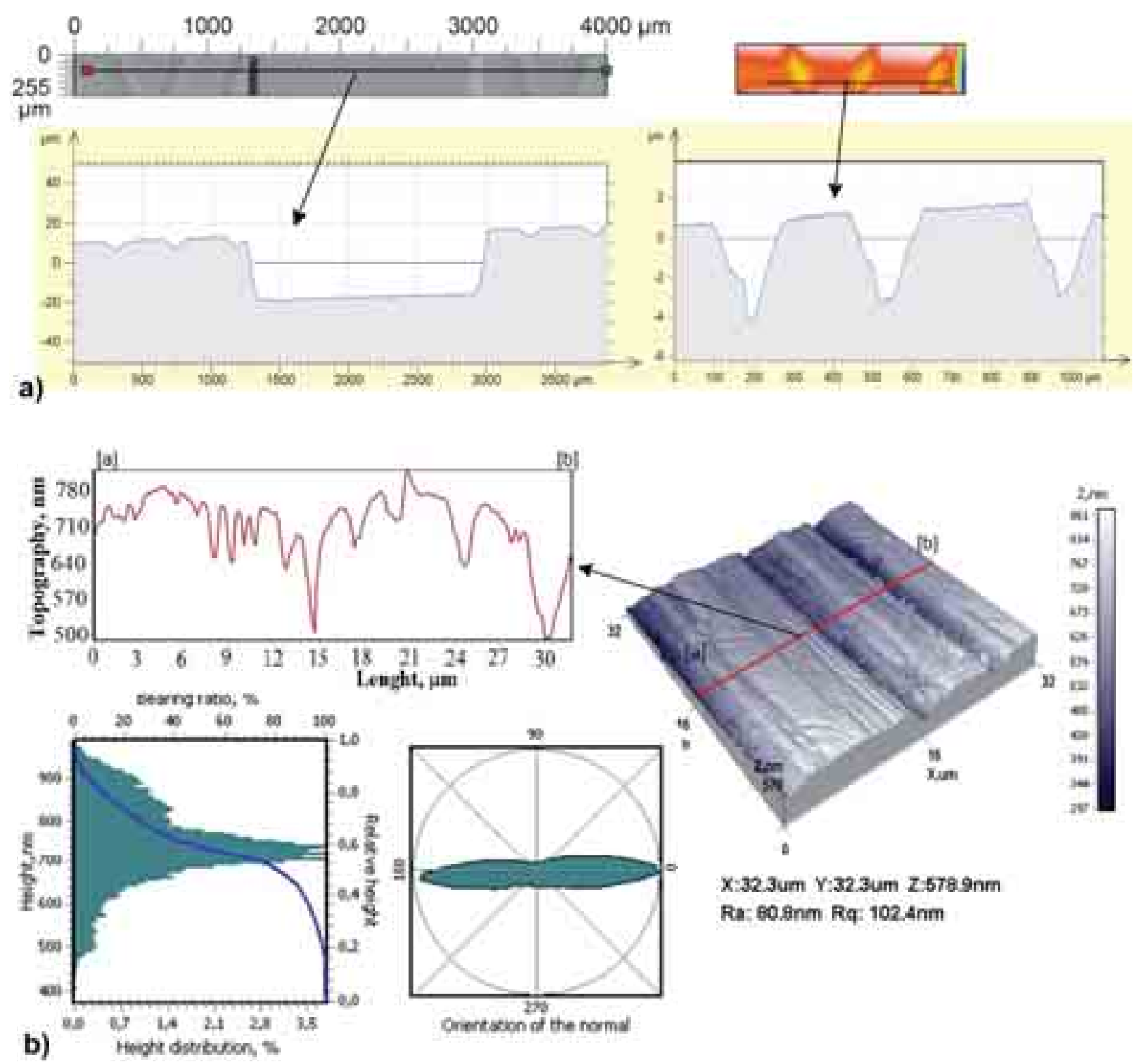

Fig. 3. Bearing sleeve's surface with micro-grooves - bearing from HDD Samsung HM160HI-continuous mode

The micro-grooves on the surface of the slide journal micro-bearing inside sleeve used in the HDD Seagate Barracuda 7200.10 ST380815AS (see Fig. 4 and 5) are about 5 $\mu \mathrm{m}$ deep and about $300 \mu \mathrm{m}$ wide and their cross-section is rectangular with the rounded apexes. The spaces between

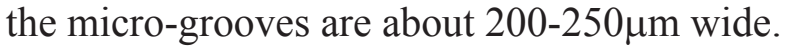

On the surface of the slide journal micro bearing inside sleeve used in the HDD Seagate Barracuda, the similar signs of wearing can be observed. The sleeve was made from $53.5 \mathrm{Cu}-45 \mathrm{Fe}-$ 1.5Sn sintered metal and journal was made from the X20Cr13 EN10250-4 material [10].

The surface topography of the measured slide journal micro-bearings journals used in HDD Samsung HM160HI are showed on the Fig. 6 and on Fig. 7 the surface topography of slide journal micro-bearings journals used in HDD Seagate Barracuda 7200.10 ST380815AS is presented.

The surface roughness of the bearing journals and sleeves measured on the AFM and defined with the $R_{a}$ and $R_{q}$ parameters is quite high and is about 80 to $200 \mathrm{~nm}$ The parameters of new and unused surfaces of bearing journal and sleeve on identical slide journal micro-bearings were in range of $R_{a}$ and $R_{q}$ and were about 4 to $25 \mathrm{~nm}$ [4]. 


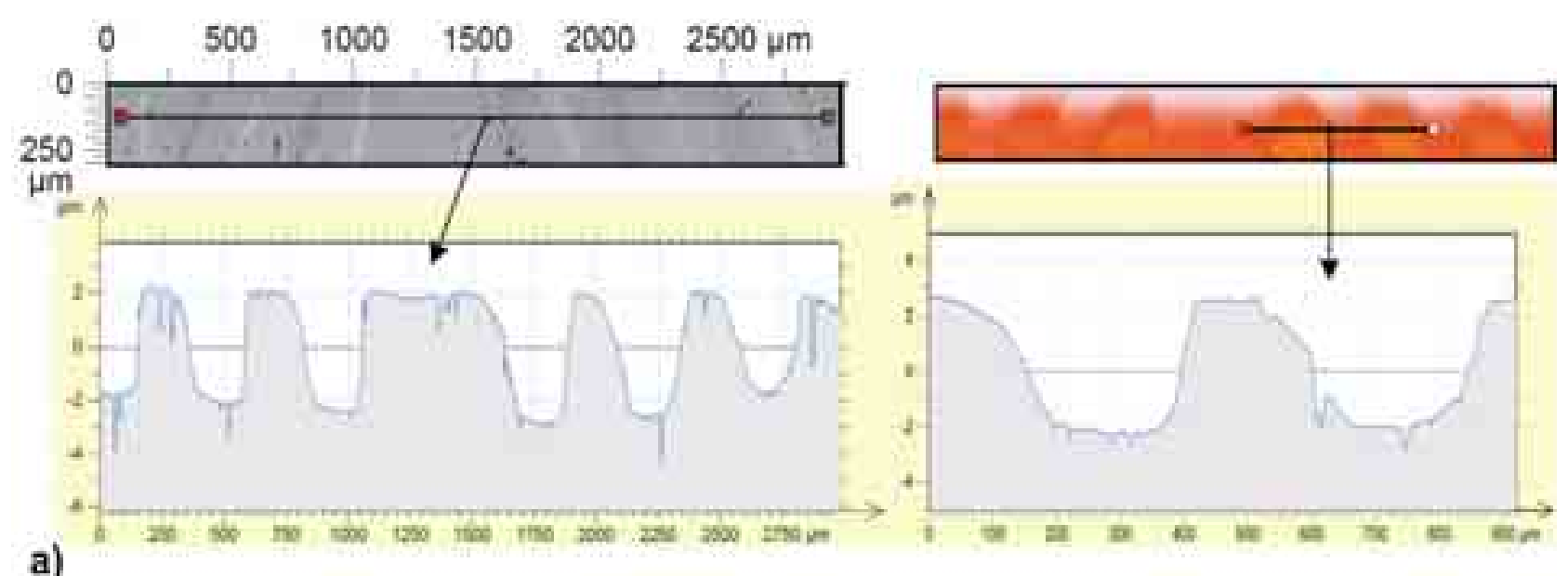

a)

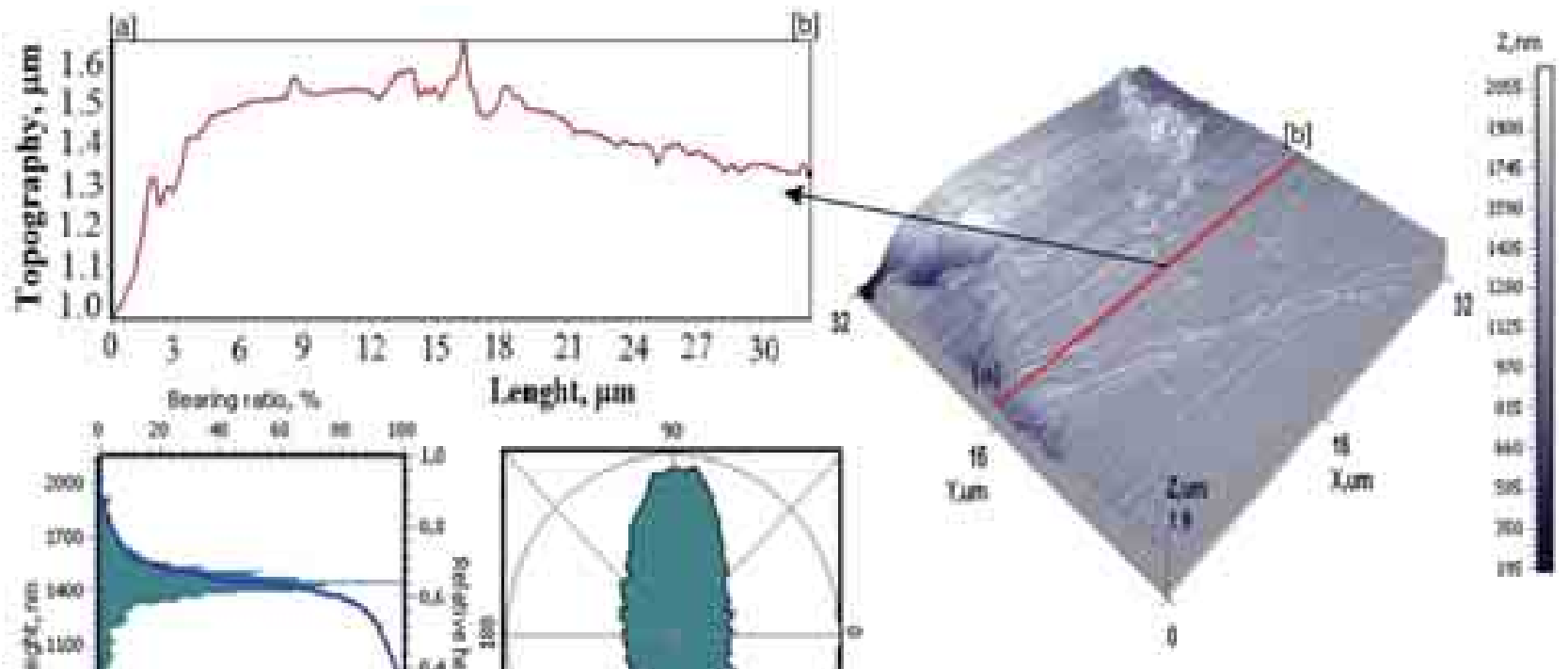

$X: 32.3 u m$ Y:32.3um Z:1.9um

b)

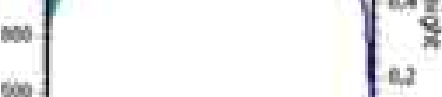

)

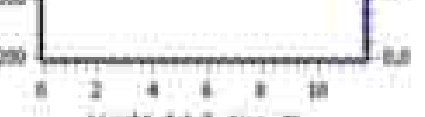

Necte ditribution 15

Ra: 0.1um Ra: $0.2 \mathrm{um}$

Fig. 4. Bearing sleeve's surface with micro-grooves - bearing from HDD Seagate Barracuda 7200.10 ST380815AScontinuous mode

\section{Conclusions and observations}

This work presents only few surface topographies chosen from dozens of made and analysed AFM scans.

The comparison of the slide journal micro-bearings journal and sleeve surface topographies presented in this work with the topographies of the identical, unused slide journal micro-bearings [4] shows, that the bearings that are working continuously has the highest rate of wearing. That rate comes from the boundary friction that comes as the result of the frequent work in nonstationary mode.

Thanks to measurements made with the use of the profilometer, the width and depth of the micro-grooves and the spaces between the micro-grooves could have been measured. The information obtained on this subject will allow simulating the accurate numerical calculations of the hydrodynamic pressure distribution in the gaps of the slide journal micro-bearings with microgrooves. 


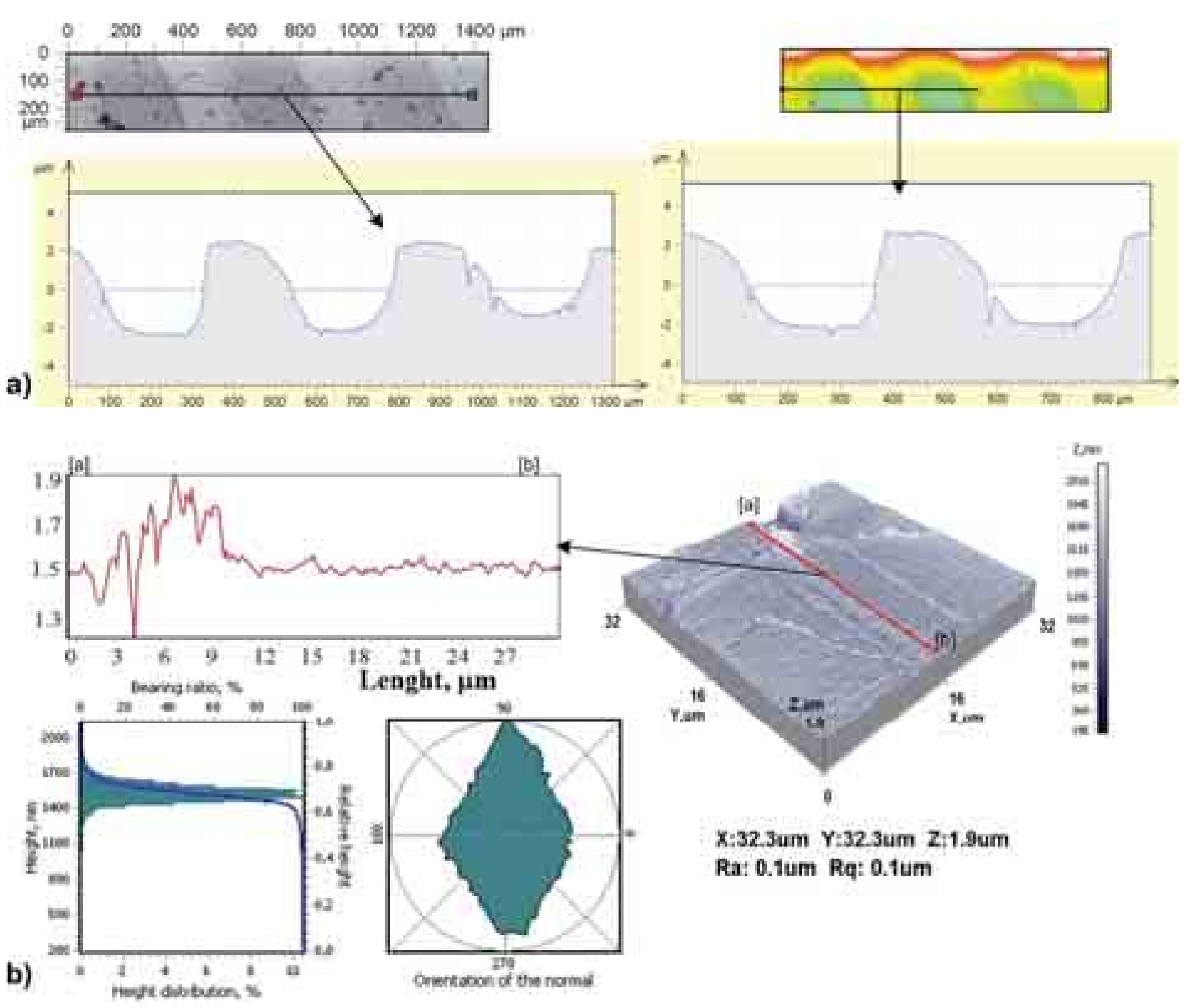

Fig. 5. Bearing sleeve's surface with micro-grooves - bearing from HDD Seagate Barracuda 7200.10 ST380815ASintermittent mode

From these distributions of roughness is possible to obtain a probability density function used in the stochastic method based on taking into account the changes in surface roughness and flow parameters of operating bearings.

\section{References}

[1] Andharia, P. I., Deheri, G. M., Gupta, J. L., Effect of Longitudinal surface Roughness on the Behaviour of Squeeze Film in a Spherical Bearing, International Journal of Applied Mechanics and Engineering, Vol. 6, No. 4, pp. 885-897, 2001.

[2] Asada, T., Saito, H., Asaida, Y., Itoh, K., Design of hydrodynamic bearing for height-speed HDD, Microsystem Technologies, 8, pp. 220-226, 2002.

[3] Chizhik, S., Khudoley, A., Kuznetsova, T., Wierzcholski, K., Miszczak, A., Micro and Nanoscale Wear Studies of HDD Slide Bearings By Atomic Force Microscopy, Proceedings of Methodological Aspects of Scanning Probe Microscopy, Heat and Mass Transfer Institute of NAS, pp. 247-252, Minsk 2010.

[4] Czaban, A., Miszczak, A., Surface Topography on Non-Operated Slide Journal MicroBearings, Journal of KONES Powertrain and Transport, Vol. 18, No. 2, pp. 109-115, 2011.

[5] Gururajan, K., Prakash, J., Surface Roughness Effects in Infinitely Long Porous Journal Bearings, Transactions of the ASME, Journal of Tribology, Vol. 121, pp. 139-147, 1999. 
[6] Jang, G. H., Lee, S. H., Kim, H. W., Kim, C. S., Dynamic analysis of a HDD spindle system with FDBs due to the bearing width and asymmetric grooves of journal bearing, Microsystems Technologies, 11, pp. 499-505, 2005.

[7] Jang, G. H., Seo, C. H., Ho Scong Lee, Finite element model analysis of an HDD considering the flexibility of spinning disc-spindle, head-suspension-actuator and supporting structure, Microsystem Technologies, 13, pp. 837-847, 2007.

[8] Miszczak, A., Analiza hydrodynamicznego smarowania ferrociecza poprzecznych łożysk ślizgowych, Monografia, Fundacja Rozwoju Akademii Morskiej, Gdynia 2006.

[9] Wierzcholski, K., Miszczak, A., Adhesion Influence on the Oil Velocity and Friction Forces in Cylindrical Microbearing Gap, Scientific Problems of Machines Operation and Maintenance, Polish Academy of Sciences, Z. 1(161), Vol.45, pp.71-79, Radom 2010.

[10] Wierzcholski, K, Miszczak, A., Khudoley, A., Characterization of nano-grooved superficial layer of computer microbearings, Tribologia, 6, pp. 257-267, Radom 2011.

[11] Wierzcholski, K., Miszczak, A., Load carrying capacity of microbearing with parabolic journal, Solid State Phenomena, Trans Tech Publications, Vols. 147-149, pp. 542-547, Switzerland, UK, USA 2009.
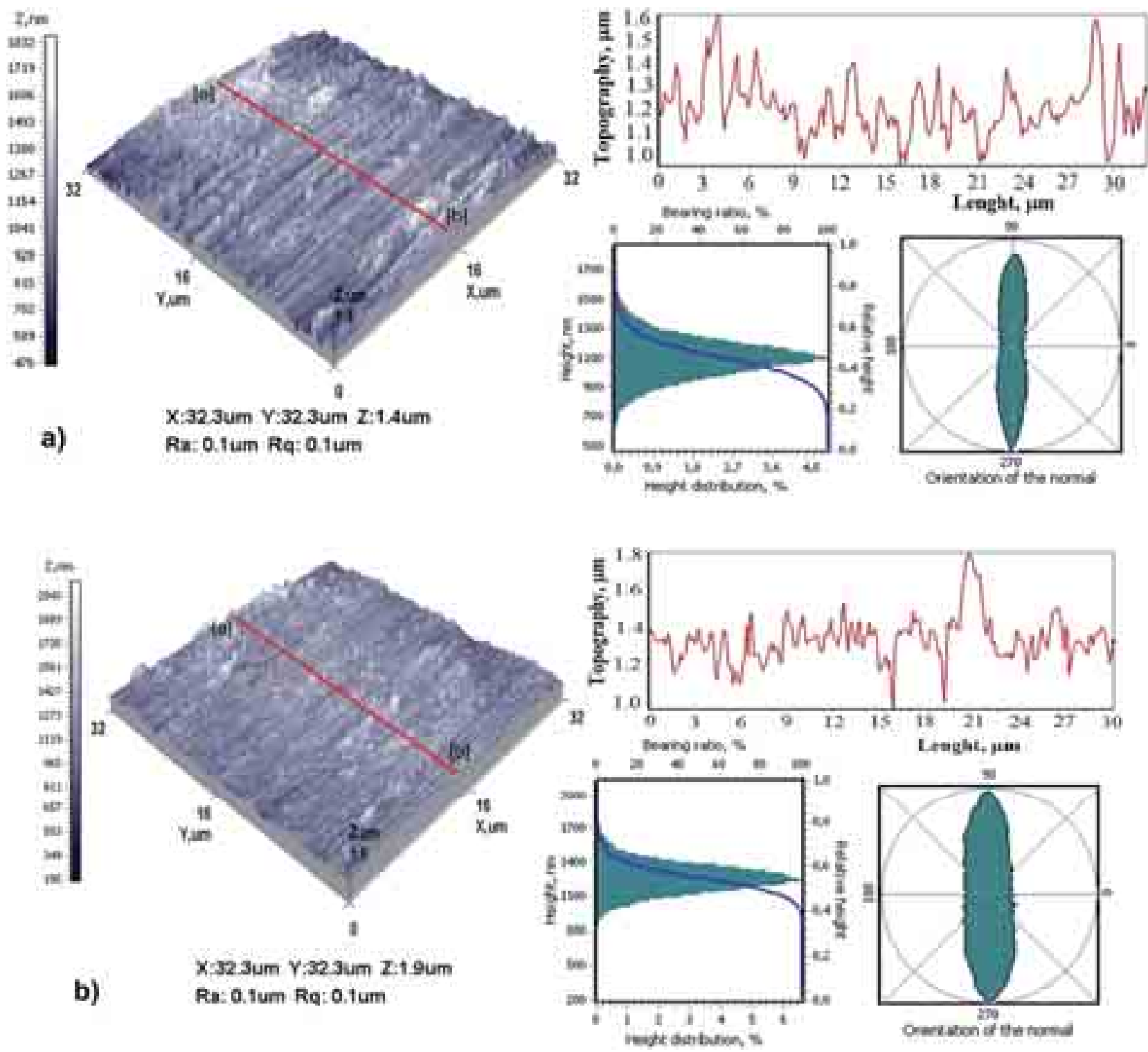

Fig. 6. Bearing journal surface topography - bearing from HDD Samsung HM160HI; a) continuous mode, b) intermittent mode 

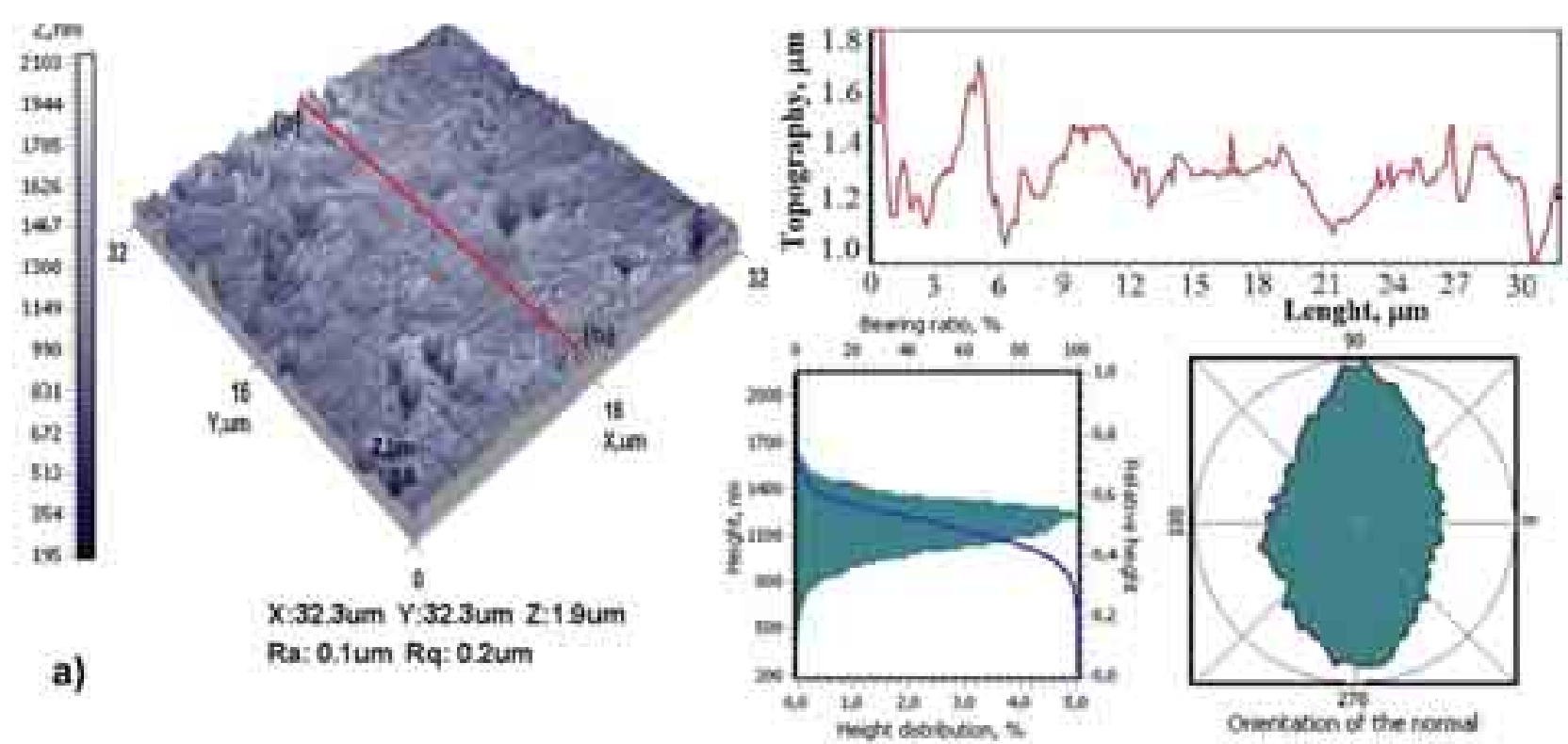

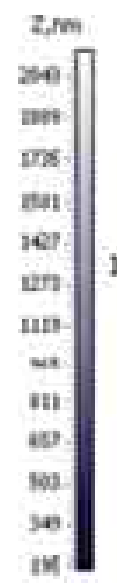

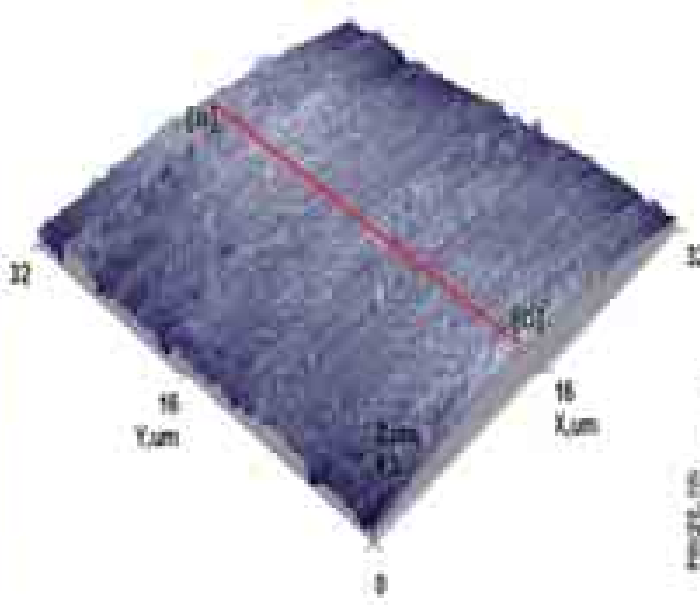

b)

X.32.3um Y.32.3um Z.19um Ra: 0.2um Rq:0.2um
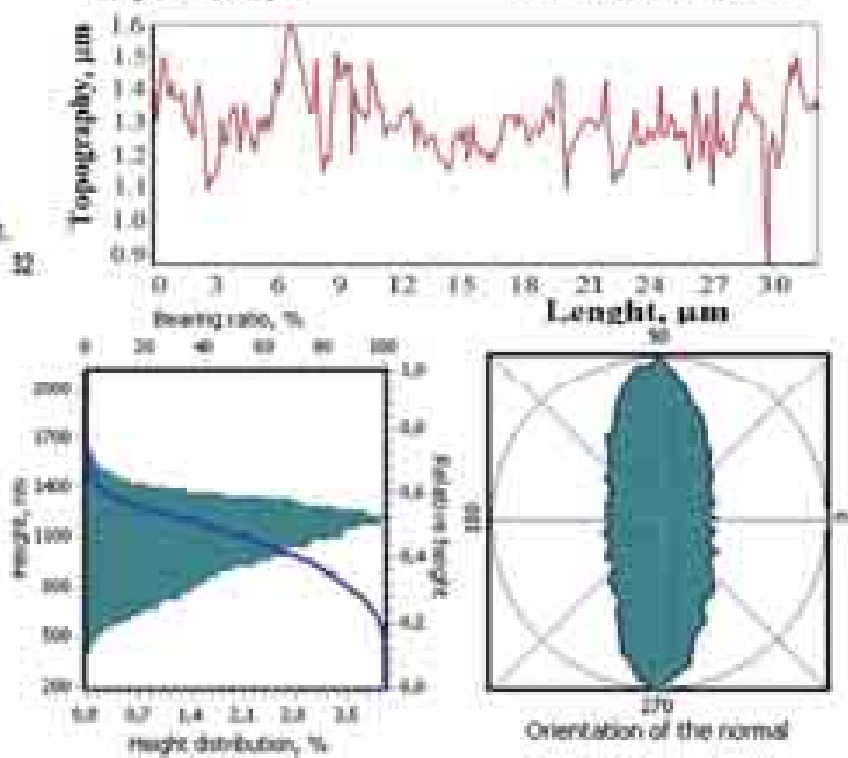

Fig. 7. Bearing journal surface topography - bearing from HDD Seagate Barracuda 7200.10 ST380815AS; a) continuous mode, b) intermittent mode 